\title{
Inhalt
}

Vorwort — VII

Abkürzungen $-\mathrm{XI}$

Einleitung -1

Märtyrer von Lyon und Vienne $177-47$

Epistulae de martyribus Lugdunensibus et Viennensibus / Briefe über die Märtyrer aus Lyon und Vienne - 49

Märtyrer von Scilli — 87

Passio Scillitanorum / Passion der Scillitaner $\longrightarrow \mathbf{8 9}$

Justin, Chariton, Charito, Euelpistos, Hierax, Paion, Liberianos und andere Märtyrer — 103

Martyrium lustini et sociorum A-C / Martyrium Justins und seiner

Gefährten A-C— 105

Pionios 129

Martyrium Pionii / Martyrium des Pionios - 133

Cyprian - 181

Acta Cypriani / Die Akten Cyprians — 185

Fructuosus, Augurius und Eulogius - 203

Passio Fructuosi, Augurii et Eulogii / Passion des Fructuosus,

Augurius und Eulogius - 205

Phileas 223

Apologia Phileae / Verteidigung des Phileas — 227

Acacius -273

Acta disputationis sancti Acacii martyris / Protokoll der Disputation mit dem heiligen Märtyrer Acacius — 275

Vierzig Märtyrer — 291

Testamentum sanctorum XL martyrum Christi Sebastorum / Testament der heiligen vierzig Märtyrer Christi von Sebaste — 293

Dativus, Saturnius und andere Märtyrer aus Abitinae - $\mathbf{3 0 7}$

Abitinensium martyrum confessiones et actus / Confessionen und Akten der abitinischen Märtyrer — 311 


\section{Areadne -361}

Martyrium Areadnes / Martyrium der Areadne - 363

\section{Maximilian -387}

Acta Maximiliani Thebestensis / Die Akten Maximilians von

Thebessa 389

\section{Aberkios -407}

Vita Abercii / Leben des Aberkios — 413

Quellen, Hilfsmittel und Literatur

1. Antike nichtchristliche Autoren und Werke -469

2. Antike christliche Autoren und Werke - $\mathbf{4 7 2}$

3. Sammeleditionen und Übersetzungen -487

4. Hilfsmittel $\longrightarrow \mathbf{4 8 8}$

5. Literatur -489

Index

Prosopographie $-\mathbf{5 3 5}$

Geographie - $\mathbf{5 4 0}$

Biblische, apokryphe, rabbinische Schriften - 542

Antike Autoren und Werke - $\mathbf{5 4 8}$ 